ISSN 0258-7122 (Print), 2408-8293 (Online)

Bangladesh J. Agril. Res. 41(2): 251-258, June 2016

\title{
EFFECT OF HONEY BEE POLLINATION AND CURD SCOOPING ON SEED YIELD OF CAULIFLOWER
}

\author{
M. A. ROUF ${ }^{1}$, M. A. RAHIM ${ }^{2}$, M. A. SIDDIQUE $^{3}$ AND M. B. MEAH ${ }^{4}$
}

\begin{abstract}
The experiment was conducted to study the effect of honey bee pollination and curd scooping on seed production of cauliflower (Brassica oleracea var. botrytis L.) cv. 'Poushali'. Eighteen combinations of treatments comprising three types of pollination viz., open pollination (natural pollination), using bees for pollination inside net (planned pollination) and plants inside net without bees (control) and six kinds of curd scooping viz., 25\%, 50\% and $75 \%$ of curd cutting, cross curd cutting, central curd cutting and no curd cutting (control). Honey bee (Apis cerana L.) was used as pollinator. Seed yield and yield attributes were significantly influenced by both factors and their combinations. Central curd cutting influenced early flowering and siliqua maturity compared to other curd cutting treatments. Planned honey bee pollination was found to inflict maximum impact on the seed production of cauliflower with an increase in seed yield of $45.46 \%$ and $23.17 \%$ higher over plants grown inside net without bees and open pollination, respectively. Central curd scooping increased $26.52 \%$ higher yield than that of no curd cutting treatment. Planned bee pollination and central curd cutting independently as well as in combination gave the maximum yield attributes of seed viz., primary and secondary flower stalks/plant, number of siliquas/plant, length of siliqua, number of seeds/siliqua,1000 seed weight, seed yield and seed germination percent of cauliflower. Planned pollination coupled with central curd cutting gave the maximum seed yield of $607.43 \mathrm{~kg} / \mathrm{ha}$ in cauliflower.
\end{abstract}

Keywords: Cauliflower, curd scooping, honey bee pollination, seed production.

\section{Introduction}

Cauliflower (Brassica oleracea var. botrytis L.) is an important cole crop in the word. It is the most popular winter vegetable in Bangladesh (Rashid, 1999). The people of Bangladesh like this vegetable due to its taste, nutritional properties and versatile usability with attractive odour of the curd. It is low in fat and calories, high in vitamin $\mathrm{C}$, and a good source of fiber, calcium and iron. In Bangladesh condition, the open pollinated (OP) variety of cauliflower can produce seeds and farmers themselves can produce seeds of OP variety of cauliflower. Ahmed and Hossain (1977) observed that the variety 'Poushali' produced the maximum quantity of seeds per plant and the germination percent of the seeds produced by 'Poushali' was found to be the best.

${ }^{1}$ Senior Scientific Officer, Hill Agricultural Research Station, Khagrachari, ${ }^{2 \& 3}$ Professor, Department of Horticulture, Bangladesh Agricultural University (BAU), Mymensingh2202, ${ }^{4}$ Professor, Department of Plant Pathology, BAU, Mymensingh-2202, Bangladesh. 
Cauliflower is a cross pollinated crop and its pollination takes place by honey bees (Singh et al., 2005). Low seed yield due to inadequate pollination is often faced as a major problem of cauliflower seed production. Inadequate pollination is caused by several factors and the most important of which includes lack of adequate number and diversity of pollinators (Sushil et al., 2013). Pollination by insects is inevitable for cauliflower seed set, since they are generally incompatible (Sihag, 2001). Bees visit plants for its food, nectar and pollen. This floral fidelity of bees is due to their preference for nectars having sugar contents and pollens with higher nutritive values. Honey bees are best known for the honey they produce. But the principal economic role of honey bees in nature is to pollinate hundreds and thousands of flowering plants and ensure seed set in quantity and quality. Both flowering plants and honey bees are interdependent for their biology and life cycle. Flowering plants offer nectar and pollen to honey bees and honey bees reciprocate their obligation by bringing about pollination and communication of the plant species. But honey bees are still of greater importance to the farmers for the pollination service they offer and increase crop yields both qualitatively and quantitatively through pollination (Sharmah et al., 2015). Supplementary pollination using honey bees in hives in the seed fields of cauliflower crop ensures good seed set and thereby seed yield is greatly increased. The effectiveness of honey bees as pollinators for cauliflower seed production has been studied by different workers in open pollinated varieties (Raula, 1972; Sharma et al., 1974; Adlakha and Dhaliwal, 1979: Kakar, 1981).

Cauliflower seed production is difficult because its flowering process goes through a curd formation. Morphological barriers such as curd compactness may be related with the seed production (Singh et al., 2005). Curd is a pre-flower primordia which often bolts slowly and incompletely (Nieuwhof, 1969). Curd rottening, irregular and delayed flower stalk emergence and empty siliqua production are some of the common problems found to be associated with cauliflower seed production (Rahman et al., 1988). Again curd scooping is one of the most important technologies employed for quality seed production of cauliflower (Chowdhury, 1979; Sinohara, 1984). Curd scooping helps in earlier bolting, easy emergence of flower stalks and early flowering and thereby getting higher seed yields (Rashid and Singh, 2000). Scooping the central portion of the curd at edible stage helps in early emergence of flower stalks (Agrawal, 1994; Moniruzzaman et al., 2007). In the absence of technical know-how of seed production technology, the production of quality seed in cauliflower is not up to the mark in Bangladesh. The present investigation was therefore, carried out to study the effect of honey bee pollination and curd scooping on the seed production of cauliflower. 


\section{Materials and Method}

The experiment was conducted at the Horticulture Farm of Bangladesh Agricultural University (BAU) during 2002-03. The land selected for the experiment was medium high land. Dhaincha (Sesbania rostrata) was grown during the kharif season before the cauliflower cultivation. The soil of the area belongs to the Old Brahmaputra alluvial tract under AEZ- 9 of Bangladesh and was silty loam in texture (sand $13.6 \%$, silt $71.4 \%$ and clay $16.0 \%$ ). The soil $\mathrm{pH}$ was 6.90. Mechanical analysis of the soil of the experimental field $(0-30 \mathrm{~cm}$ depth) was performed in the Humbldt Soil Testing Laboratory, Department of Soil Science of BAU. The treatments consisted of three types of pollination viz., $\mathrm{P}_{0}=$ open (natural) pollination, $\mathrm{P}_{\mathrm{b}}=$ using bees for pollination inside net (planned pollination) and $\mathrm{C}=$ plants inside net without bees (control) and six kinds of curd scooping viz., $S_{1}=25 \%$ or $1 / 4$ portion of a curd cutting, $S_{2}=50 \%$ or $1 / 2$ portion of a curd cutting, $S_{3}=75 \%$ or $3 / 4$ portion of a curd cutting, $S_{4}=$ cross curd cutting i.e., $2 \mathrm{~mm}$ breadth cutting on the curd just like a ' $\mathrm{X}$ ', $\mathrm{S}_{5}=$ central curd cutting i.e., $2 \mathrm{~cm}$ diameter round cutting from the central portion of the curd and $\mathrm{S}_{0}=$ without curd cutting (control). So there were 18 treatment combinations in all. The mosquito net was used in the experiment. In case of treatment $\mathrm{P}_{\mathrm{b}}$, the unit plots were caged with mosquito nets along with honey bees (Apis cerana L.) during flowering period. Bee hives of A. cerana were borne to every unit plots of $\mathrm{P}_{\mathrm{b}}$ treatment and bees were allowed to go inside the net, and thereafter the net was closed. But in case of ' $\mathrm{C}$ ' treatment, the unit plots were caged with mosquito net where no pollinators (honey bees) were allowed. Unit plots of $\mathrm{P}_{0}$ treatment were kept as natural open condition. The experiment was laid out in Randomized Complete Block Design with three replications.

The unit plot size was $3.0 \mathrm{~m} \times 2.4 \mathrm{~m}$ accommodating 20 plants per plot with a spacing of $60 \mathrm{~cm} \times 60 \mathrm{~cm}$. The test variety was 'Poushali' which is an open pollinated (OP) variety. Forty day-old seedlings were transplanted on 25 October, 2002. The land was fertilized by well decomposed cowdung with doses $20 \mathrm{t} / \mathrm{ha}$, and N, P, K, B and Mo with 68, 50, 110, 3 and $0.78 \mathrm{~kg} / \mathrm{ha}$. The sources of N, P, $\mathrm{K}, \mathrm{B}$ and Mo were urea, TSP, MoP, borax and sodium molybdate. The whole amount of $\mathrm{P}$ and half of the cowdung were incorporated to the soil during final land preparation and the remaining half of cowdung and one-third of each $\mathrm{N}$ and $\mathrm{K}$ were applied to the pit while the rest of $\mathrm{N}$ and $\mathrm{K}$ were top dressed in two equal installments at 21 and 45 days after transplanting. One additional dose of $\mathrm{N}$ (45 $\mathrm{kg} / \mathrm{ha}$ ) and MoP (50 kg/ha) was applied during flowering of cauliflower. The crop after transplanting was irrigated daily by a watering can up to 6 days and then twice a week and later once a week. The crop was irrigated within 3-4 days of mulching and fertilizer application. Excess water during the rain was drained out to avoid water stagnation. The other intercultural operations and plant protection measures were taken as and when necessary. The seed crop was harvested on 2-5 April, 2003. 
Data were taken on days to $50 \%$ flowering, days to siliqua maturity, number of primary and secondary flower stalks/plant, number of siliquas/plant, length of siliqua $(\mathrm{cm})$, number of seeds/siliqua, 1000 seed weight, seed germination (\%), seed yield/plant $(\mathrm{g})$ and seed yield/ha. The data were taken randomly from 10 plants of each plot. After seed harvest, seed germination test was done in the laboratory of the Horticulture Department of BAU. Data were analyzed by using statistical package programme MSTAT-C. Mean separation was done by Least Significant Difference (LSD) test at 5\% level of probability.

\section{Results and Discussion}

\section{Effect of honey bee pollination}

All the parameters differed significantly in pollination treatments (Table 1). Days to $50 \%$ flowering (75.09) and days to siliqua maturity (152.50) were found the maximum in the treatments of plants inside net without bees and open (natural) pollination, respectively. Number of primary (8.14) and secondary (71.15) flower stalks/plant, number of siliquas/plant (719.22), length of siliqua $(5.62 \mathrm{~cm})$, number of seeds/siliqua (11.04), 1000 seed weight $(3.57 \mathrm{~g})$, seed germination $(90.20 \%)$, seed yield/plant $(18.80 \mathrm{~g})$ and seed yield/ha $(456.20 \mathrm{~kg})$ were recorded highest when the plants were grown inside net supplying bees for pollination, and the minimum values for all the parameters except seed germination were recorded from the plants grown inside net without supplying bees for pollination. It was seen that planned pollination increased $8.97 \%$ and $32.49 \%$ higher fruit setting compared to open (natural) pollination and plants grown inside net without bees (control). Again planned pollination increased $3 \%$ and $45.45 \%$ higher seed setting than those of natural pollination and control. These corroborate the results of Sushil et al. (2013) who obtained $12.50 \%$ pod setting and $12.25 \%$ seed setting higher in planned pollination than those of natural pollination in broccoli. In respect of seed yield/plant, planned pollination increased $19.26 \%$ and $46.33 \%$ higher seed yield than that of natural pollination and control. The result of the highest seed yield might be due to better pollination and good fruit setting. This is in agreement with the results of Sharma et al. (1974) and Kakar (1981). Planned pollination gave $45.46 \%$ and $23.17 \%$ higher seed yield over control (plants inside net without bees) and natural pollination, respectively. This is in agreement with the report of Sushil et al. (2013).

\section{Effect of curd scooping}

All the parameters differed significantly in curd cutting treatments (Table 2). The treatment without cutting of curd (control) took the maximum days (76.63) to reach $50 \%$ flowering stage which was closely followed by $75 \%$ cutting of curd (75.84) and the central curd cutting took the minimum days (69.88) to reach $50 \%$ 
flowering stage (Table 2). Similar result was also found in case of days to siliqua maturity. Curd scooping helped in easier bolting, easy emergence of flower stalk and early flowering. This corroborates the result of Rashid and Singh (2000). Central curd cutting gave the maximum number of primary and secondary flower stalks/plant (8.17/plant and 77.74/plant), number of siliquas (735.84/plant), length of siliqua $(5.83 \mathrm{~cm})$, number of seeds/siliqua (12.89), 1000 seed weight $(3.58 \mathrm{~g})$ and seed germination $(91.12 \%)$ which were followed by cross cutting of curd and their minimum values were obtained from $75 \%$ cutting of curd except 1000 seed weight and seed germination. The treatment without curd scooping gave the lowest 1000 seed weight $(3.12 \mathrm{~g})$ and seed germination $(84.13 \%)$. The maximum seed yield $(19.34 \mathrm{~g} / \mathrm{plant}$ and $462.87 \mathrm{~kg} / \mathrm{ha})$ were recorded in central curd cutting treatment followed by cross cutting of curd while the minimum seed yield $(8.98 \mathrm{~g} / \mathrm{plant}$ and $211.96 \mathrm{~kg} / \mathrm{ha})$ was recorded from the plants with $75 \%$ curd cutting (Table 2). It was seen that $75 \%$ curd cutting gave inferior result compared to without curd cutting in terms of seed yield. Central curd scooping increased $54.16 \%$ and $26.52 \%$ higher yield than that of $75 \%$ curd cutting and control treatment, respectively. These results are in agreement with Rahman et al. (1988) and Moniruzzaman et al., 2007) who got higher values for the aforementioned parameters in the central curd cutting. The result also clearly revealed that curd scooping had positive effects on the yield and quality of cauliflower seeds. This might be due to the fact that flower stalks produced from the scooped curd were not as compact as the no scooped curd and got more space which decreased competition among the flower stalks resulting more seed yield in cauliflower.

\section{Combined effect of honey bee pollination and curd scooping}

The combination $\mathrm{CS}_{0}$ required the maximum days to $50 \%$ flowering (77.06) and siliqua maturity (154.36), and $\mathrm{P}_{\mathrm{b}} \mathrm{S}_{5}$ combination took the minimum days (67.55) to reach $50 \%$ flowering and siliqua maturity stages (148.20) (Table 3). Number of primary (9.76) and secondary flower stalks/plant (86.85), number of siliquas/plant $(888.63)$, length of siliqua $(6.44 \mathrm{~cm})$, number of seeds/siliqua (15.60), 1000-seed weight (3.72g) and seed germination (94.44\%) were found maximum from $\mathrm{P}_{\mathrm{b}} \mathrm{S}_{5}$ combination followed by $\mathrm{P}_{\mathrm{b}} \mathrm{S}_{4}$ combination and their minimum values were obtained from $\mathrm{CS}_{3}$ combination. But in case of length of siliqua, 1000 seed weight and seed germination, the minimum values were recorded from $\mathrm{CS}_{2}$ and $\mathrm{CS}_{0}$ combinations. The combination $\mathrm{P}_{\mathrm{b}} \mathrm{S}_{5}$ gave the maximum seed yield $(25.99 \mathrm{~g} / \mathrm{plant}$ and $607.43 \mathrm{~kg} / \mathrm{ha})$ which was followed by $\mathrm{P}_{\mathrm{b}} \mathrm{S}_{4}$ combination and the combination $\mathrm{CS}_{3}$ gave the minimum seed yield (Table $3)$. As all the seed yield attributes were higher in the plants grown with using bees for pollination inside net with central curd scooping $\left(\mathrm{P}_{b} \mathrm{~S}_{5}\right)$, those seed yield attributes combinedly resulted in the maximum seed yield in the same treatment combination. 


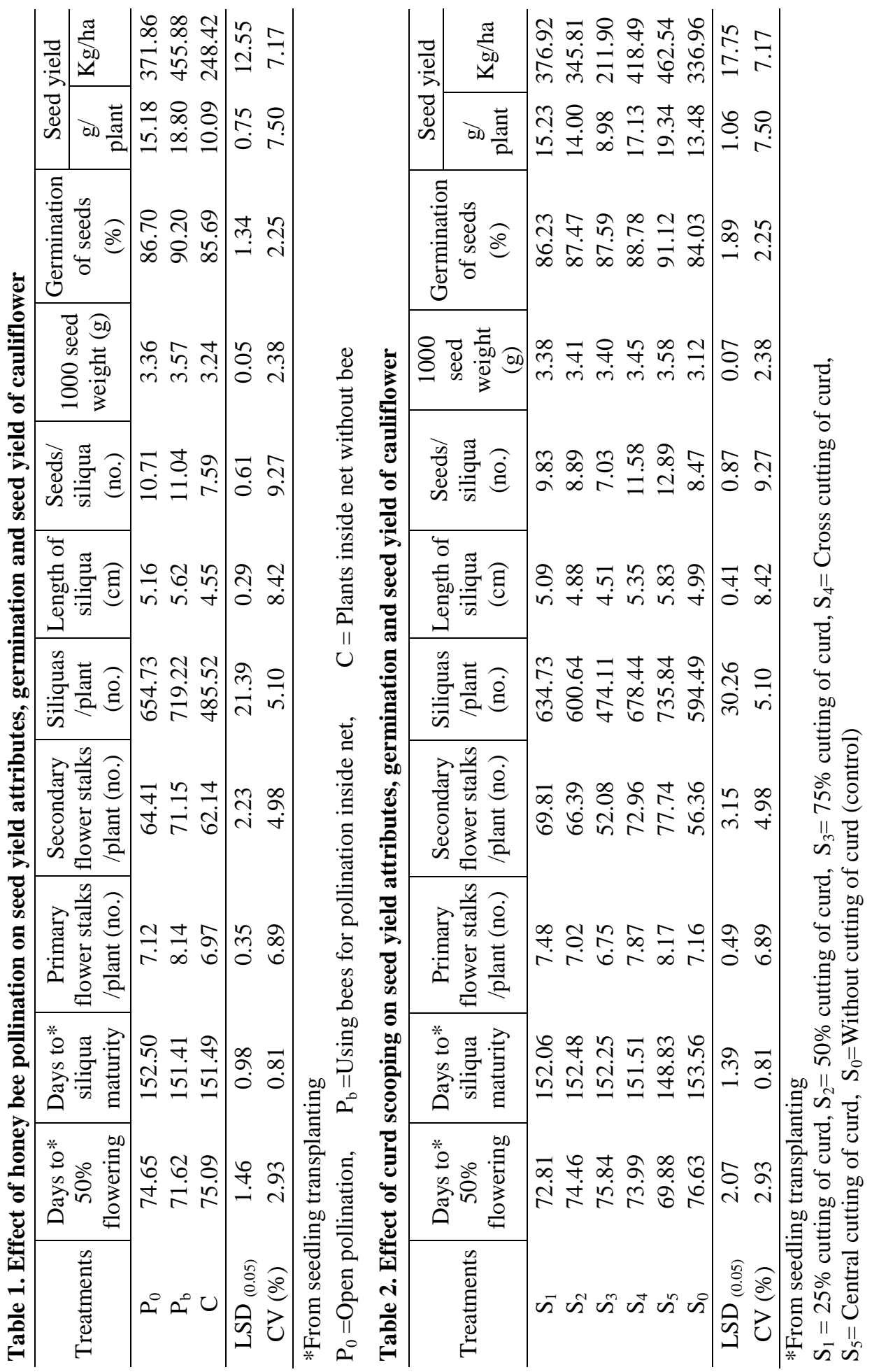




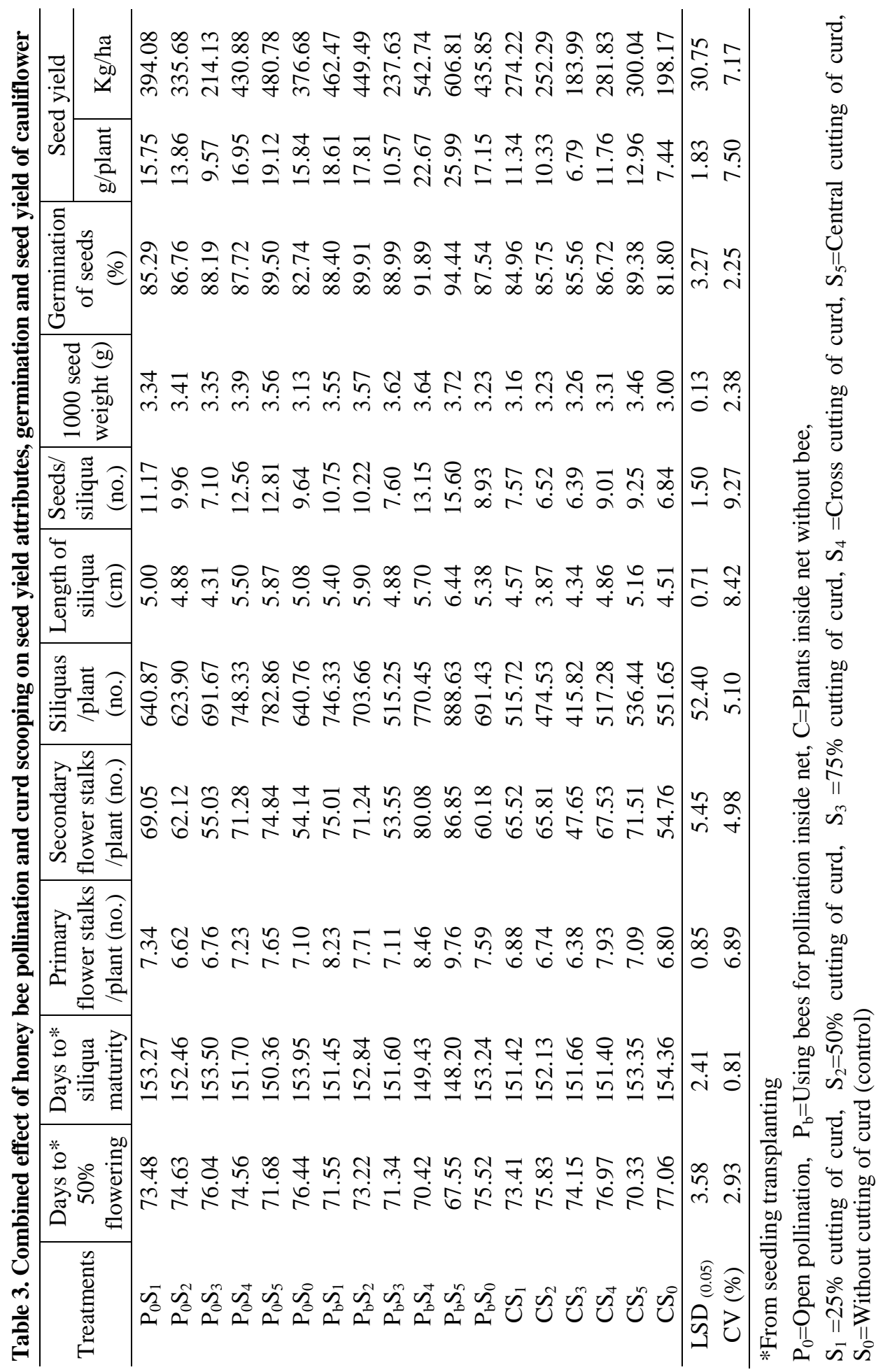




\section{Conclusion}

From the above study it can be concluded that honey bee pollination and curd scooping are imperative for higher seed yield and quality seed production of cauliflower. Keeping bees inside net (planned pollination) and central curd scooping could be practiced for better and quality seed production of cauliflower.

\section{References}

Adlakha, R.L. and H.S. Dhaliwal. 1979. Insect pollination of seed cauliflower (Brassica oleracea var. botrytis) with particular reference to the role of honeybees. Indian Bee J. 41: 13-16.

Agrawal, R.L. 1994. Seed Technology. $2^{\text {nd }}$ edition. Oxford \& IBH Publishing Co., New Delhi, India. Pp.61-249.

Ahmed, S.U. and A. Hossain. 1977. Production of seeds of early cauliflower varieties in the Mymensingh area. Bangladesh Hort. 59 (20): 41-43.

Chowdhury, B. 1979. Vegetables. National Book Trust, New Delhi, India, Pp. 64-72.

Kakar, K.L. 1981. Foraging behaviour of insect pollination of cauliflower bloom. Indian J. Ecol. 8: 126-130.

Moniruzzaman, M., Z.A. Firoz, A.S.M.H.Rashid and G.M.A. Halim. 2007. Effect of planting time and curd scooping on seed production of cauliflower var. BARI Fulkapi-1. J. Sci. technol (Dinajpur). 5: 67-73.

Nieuwhof, M. 1969. Cole Crop. Leonard Hill, London. Pp. 57-59.

Rahman, M.A.K.M., S.M.M. Hossain and M.M. Hoque. 1988. Effect of different curd cutting methods on production of cauliflower seeds. Bangladesh Hort. 16 (1): 50-53.

Rashid, M.A. and D.P. Singh. 2000. A Manual on Vegetable Seed Production in Bangladesh. Karshaf Printers (Pvt.) Ltd. Dhaka. P. 119.

Rashid, M.M. 1999. Sabji Biggayan (In Bengali). Rashid Publishing House. 94 Old DOHS, Dhaka-1206. P. 223.

Raula, T.S. 1972. Pollination studies in cauliflower (Brassica oleracea var. botrytis L.), J. Res. Punjab Agril. Univ. 9: 580-585.

Sharma, A.K., H.S. Dhaliwal and K.L. Kakar. 1974. Insect visitors and pollinators of cauliflower (Brassica oleracea var. botrytis L.) seed crop bloom. Himachal J. Agril. Res. 2: 74-78.

Sharmah, D., A. Khoumd, S. Rahman and P. Rajkumari. 2015. Significance of honey bee as a pollinator in improving horticultural crop productivity in N. E. Region, India: A review. Asian J. Natural Applied Sci. 4(1): 62-69.

Sihag, R.C. 2001. Why should bee-keeping be utilized as an input in agriculture? Current Sci. 81: 1514-1516.

Singh, B., A.K. Singh, S. Pandey and M. Rai. 2005. Effect of curd cutting techniques at different curd stages on seed production in Indian cauliflower (Brassica oleracea var. botrytis L.). Veg. Sci. 32(1): 80-81.

Sinohara, S. 1984. Vegetable Seed Production Technology in Japan elucidated with Respective Variet Development Histone particular. Sinohara's authorized agricultural Consulting engineer Officce, 4-7-7, Nishiooi, Shinagawa-Ku, Tokyo, Japan. Ref. No. 4 (iii), vol. 1.

Sushil, S.N., J. Stanley, N.K. Hedau and J.C. Bhatt. 2013. Enhancing seed production of three brassica vegetables by honey bee pollination in north western Himalayas of India. Universal J. Agril. Res. 1(3):49-53. 